\title{
One of the most significant discoveries in Developmental Biology from an Indian laboratory - Iqbal A. Niazi and the role of retinoids in limb regeneration
}

\author{
SURENDRA GHASKADBI ${ }^{1}$ and VIDYANAND NANJUNDIAH ${ }^{*, 2}$ \\ ${ }^{1}$ Developmental Biology Group, MACS-Agharkar Research Institute, Pune, India and \\ ${ }^{2}$ Centre for Human Genetics, Bangalore, India.
}

\begin{abstract}
In this short commentary, we reflect upon the fascinating paper by I.A. Niazi entitled "Background to work on retinoids and amphibian limb regeneration: Studies on anuran tadpoles - a retrospect." originally published in J. Biosciences (1996), and herein reproduced with the kind permission of the author and the Journal of Biosciences. It is fitting that this landmark publication is included in this India-related Special Issue of the Int. J. Dev. Biol., because it sketches the background to what is arguably one of the two most significant discoveries in Developmental Biology to come from an Indian laboratory. Besides being of intrinsic interest, it spawned an entire area of research, one that deals with the role of retinoids in morphogenesis and development generally.
\end{abstract}

KEY WORDS: I.A. Niazi, retinoid, vitamin A, development, regeneration

Iqbal Ahmad Niazi's interest in growth and development was sparked by the lectures of Prof. Babar Mirza which he attended as an undergraduate student of Zoology in Aligarh Muslim University. He was fascinated by metamorphosis, and had started observations of his own on butterfly larvae. After obtaining a Master's, also at Aligarh, he went on to do a PhD at McGill University. Prof. Norman Berrill, his research supervisor, had suggested an investigation of tail regeneration in the lamprey. During the stay at McGill, he had come across a report that feeding cod liver oil could inhibit thyroid development and delay metamorphosis in tadpoles. On his return to India, he decided to take up the effect of vitamin A (the term for one among any of a set of compounds including retinol, retinal and retinoic acid) on development and regeneration in amphibians.

As he explains, for about a decade starting in 1967, his may have been the only laboratory in which a systematic study of vitamin $A$ in relation to regeneration was carried out. While Niazi and his students were engaged on their experiments in Jaipur, biochemical and physiological aspects of vitamin A were being investigated in the laboratories of H.R. Cama and J.N. Ganguly in the Indian Institute of Science, Bangalore. Both sets of researchers were interested in the teratological correlates of vitamin Aadministration, but it appears that they were unaware of each other's interests. A reason may have been that they used very different systems: the frog in one case, the rat and the chick in the other. Also, their primary interests concerned development and nutrition, respectively. In relation to regeneration, the question Niazi asked himself was: can the capacity of anuran tadpoles to regenerate limbs be prolonged by the administration of vitamin A? It turned out that it could, but the experiments yielded two other findings. Both were serendipitous, answers to questions that had not been asked.

When applied during regeneration, vitamin A not only allowed proximal structures to develop (thereby violating the 'rule of distal

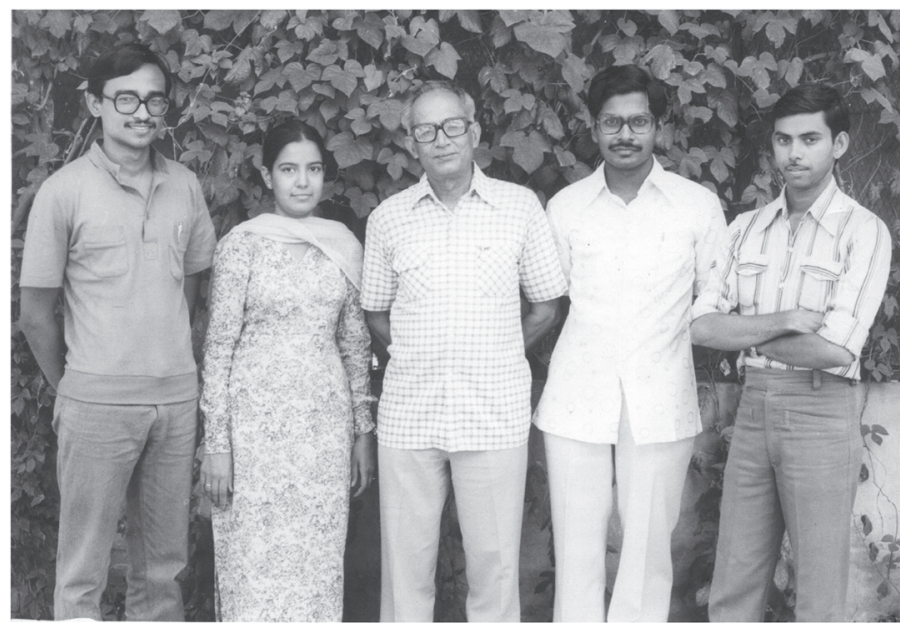

Fig. 1. Iqbal Ahmad Niazi with students (University of Rajasthan, Jaipur, 1983). From left to right: Sagar Mal Lahiri, Shaheen Alam, IAN, Charles Ratnasamy and Krishan Kumar Sharma.

\footnotetext{
*Address correspondence to: Vidyanand Nanjundiah. Centre for Human Genetics, Bengaluru, India. e-mail: vidyan@alumni.iisc.ac.in (iD) https://orcid.org/0000-0003-0224-153X
} 
transformation'), but - sensationally - the regenerate could be a mirror-imaged duplicate limb. The results were published and remained largely unnoticed, confirming the unfortunate truth that sometimes, where a paper appears can be more important than what it says. Even when cited, the original finding tended to be mentioned only in passing. Maden has written a reminiscence in which he draws attention to this (Maden, 2002). T.S. Okada's historical account of regeneration studies from a developmental biology perspective assesses the significance of the discovery thus: "The impact which the vitamin A experiment gave was immediate, great and very broad. In regeneration studies, for the first time in a very long history, we created an experimental system which enabled the manipulation of pattern by a mere extrinsic agent, vitamin A" (Okada 1996). The other discovery alluded to at the start, the discovery of a homeotic transformation induced by vitamin A in the regenerating tadpole tail, was directly stimulated by this one. A report of it appears elsewhere in this Special Issue (Mohanty-Hejmadi, 2020). We are grateful to Prof. Niazi for sharing his reminiscences with us.

\section{References}

MADEN, M. (2002) Retinoic Acid and Limb Regeneration - a personal view. Int. J. Dev. Biol. 46: 883-886.

MOHANTY-HEJMADI, P. (2020). Introduction of Developmental Biology at Utkal University, (Odisha, India). Int. J. Dev. Biol. 64: 59-64.

NIAZI, I.A. (1996). Background to work on retinoids and amphibian limb regeneration: Studies on anuran tadpoles - a retrospect. Journal of Biosciences 21: 273-297.

OKADA, T. S. (1996). A brief history of regeneration research-For admiring Professor Niazi's discovery of the effect of vitamin A on regeneration. J. Biosci. 21:261-271. 
J. Biosci., Vol. 21, Number 3, May 1996, pp 273-297. ( P Printed in India.

\title{
Background to work on retinoids and amphibian limb regeneration: Studies on anuran tadpoles-a retrospect
}

\author{
I A NIAZI* \\ Department of Zoology, University of Rajasthan, Jaipur, 302004, India \\ *Present address: D-2/2276, Vasant Kunj, New Delhi 110070, India \\ MS received 5 October 1995; revised 7 February 1996
}

\begin{abstract}
Studies on the effects of exogenous vitamin A palminate on limb development and regeneration in anuran tadpoles carried out since late 1960s at the author's laboratory are reviewed and discussed. Most significant was the initial discovery that vitamin A causes regeneration of complete or nearly complete limbs instead of only the missing distal part, thus altering the P-D pattern of regeneration-a phenomenon now called proximalization. Often more than one such regenerates develop per stump. Vitamin A produces proximalizing effect on regeneration cells during their dedifferentiation and blastema formation but inhibits regeneration if given once redifferentiation begins. Shank-level blastemas from treated tadpoles grafted into orbits of previously treated/untreated host tadpoles formed complete limbs. Proximalizing effect is proportionate to vitamin A concentration, duration of treatment, amputational level and stage of tadpoles. Vitamin A produces this effect also if given only prior to amputation. Its influence persists after cessation of treatment, declining with time. Proximalizing effect is correlated with natural ability in limbs to regenerate. Vitamin $\mathbf{A}$ improves regenerative ability and can induce it to some extent in non-regenerating limbs. Vitamin A excess retards limb development and produces stage dependent teratogenic defects. Further development of only that limb region is prevented in which differentiation is beginning when vitamin $A$ is given. Short treatment of tadpoles beginning with limbs at spatula/paddle stage inhibited foot development in the unoperated limbs hut promoted regeneration of complete limbs from the contra-lateral amputated limbs. These dual effects were due to cells of the former differentiating and of the latter dedifferentiating when exposed to vitamin A palmitate.
\end{abstract}

Keywords. Retinoids; pattern formation; limb regeneration; anuran tadpoles.

\section{Introduction}

The last 15 years have witnessed an explosion of research on the effects of retinoids (vitamin A and deriatives) on pattern formation in the regenerating amphibian limbs and various other developing systems in chordates. This great interest in the retinoids has been generated by the remarkable discovery that contrary to the general rule of limb regeneration in amphibians, formulated by Rose (1962) as the Rule of Distal Transformation of Blastema, treatment of amphibians with exogenous retinoids after limb amputation can cause the blastema to regenerate complete limbs instead of only the missing distal part, thus duplicating the proximal structures in the regenerate. Frequently, more than one (usually mirror imaged twins) are regenerated from the same stump. Thus the retinoids cause specific alteration in the pattern of regenerating limbs. These changes along specific axes (P-D, A-P, D-V) can be produced predictably and are repeatable. Due to this property to modify pattern predictably along well defined axes in a developing system, retinoids are reliable chemical probes to discover the molecular mechanism(s) of pattern generation during development. Recent studies 
on these lines have indeed led to a great advance in our knowledge regarding this fundamental problem of development. Retinoic acid (RA) appears to be vitally involved in pattern formation. Exogenous RA can regulate in a specific manner the expression of a number of homeobox genes implicated in pattern generation. Gradients of endogenous RA have been observed in the chick wing bud and regenerating amphibian limb (Brockes 1989; Tabin 1991; Tickle 1992; Eichele 1993; Scadding and Maden 1994). Most remarkably, retinoid treatment of frog tadpoles after tail amputation has been discovered to cause homeotic transformation of tail cells to form limbs (Mohanty-Hejmadi et al 1992; Maden 1993).

The discovery of the remarkable property of retinoids to influence pattern formation in a specific manner is one of the most significant contributions of regeneration studies in the field of developmental biology. The investigations on the effects of vitamin A (retinol) on regenerating systems (tail and limb) in anuran tadpoles were initiated for the first time in my laboratory at the Department of Zoology of the University of Rajasthan, Jaipur, around 1967; and until early 1980s ours was perhaps the only laboratory where such research was carried out. Until my retirement from the University some years ago, I was involved in these studies in collaboration with several students who joined for research in the area of regeneration for their doctoral degrees under my guidance. The initial discovery of the remarkable property of vitamin A to cause regeneration of complete limb after shank-level amputation came from the results of an experiment made at this laboratory (Niazi and Saxena 1978). Our studies have made important contributions on various aspects of the effects of retinoids on developing and regenerating limbs in anuran tadpoles from which certain principles have emerged (Niazi 1983; Niazi et al 1989; Maden 1989).

I have often been asked why E chose vitamin A to study its effects on regeneration of limbs or tail. One of the objectives was to investigate the effects of this chemical on the embryos and tadpoles of anuran amphibians. Studies on its effects on the ontogenetic development as also regeneration of limbs and tail in the tadpoles formed part of the programme. The choice of vitamin A was motivated by the known harmful effects of its excess in mammals including humans. It was well established that among other functions (maintenance of epithelial differentiation, vision, growth, reproduction etc.) vitamin A was also essential for normal embryonic development and proper morphogenesis; but both hypo- and hyper-vitaminoses A during embryogenesis were teratogenic in mammals. Administration of excessive amounts of this vitamin to pregnant rodent mammals caused a variety of severe defects, including those of limbs, in the offsprings. Limb defects were often similar to those produced in humans by intake of thalidomide by mothers during pregnancy. The specific abnormalities depended on the dose and developmental stage of the affected tissues/organs when the vitamin was given. The embryonic mesoderm was observed to be the primary tissue affected (Cohlan 1953; Kalter and Warkany 1959; Giroud and Martinet 1960; Takekoshi 1964; Marin-Padilla 1966).

In addition, a series of studies since early 1950s had shown that exogenous vitamin A also produces a number of other effects on cells and tissues of avian and mammalian embryos and adults in vivo and in vitro. Excess of this vitamin had been discovered to destabilize cell membranes, stimulate synthesis and release of lysosomal enzymes into extra-cellular environment, cause dissolution of bone and cartilage due to degradation of the matrix by the released lysosomal hydrolases, including cathepsins, liberating cells capable of mitosis. Increased mitosis in certain vitamin A treated tissue explants 
in vitro also was observed in some studies (review: Fell and Renaldini 1965). Several decades earlier, McCarrison (1923) had found that feeding cod-liver oil (a rich store of vitamin A) to frog tadpoles retarded the development of thyroid glands, delaying or preventing metamorphosis. Hypervitaminosis A was reported to cause reduction in thyroid size in mammals also. Results of some experiments during 1930s on frog tadpoles given vitamin A and thyroxine together had suggested probable antagonism between the two (review: Drill 1943).

As for other teratogens, the mechanism of action of vitamin A that causes defects during development was not well understood. Developmental studies on a variety of animals can be useful for the analysis of the problems of teratology in humans. Amphibians have been very useful animals for investigations on a variety of problems of development. The teratogenicity of vitamin A or any of its derivatives on the development of embryos or larvae of any amphibian had not been tested until late 1960s.

This was the consideration that motivated us to begin studies on the effects of exogenous vitamin A on the development in embryos and tadpoles of anurans, particularly of the limbs. Investigation of the effects on limb and tail regeneration was to be the major part of this programme. The basic processes in the development of limbs in all tetrapod vertebrates are identical. If the development of amphibian limbs were affected by vitamin A in the same way as in mammals they could perhaps be useful models to investigate the mechanism of its teratogenic action.

The studies on limb regeneration were included in the programme because virtually all the phenomena and problems associated with development in vertebrate embryos are inherent in the regeneration of an amphibian limb. The processes of differentiation and morphogenesis of regenerating limb are similar to those which occur during ontogeny. Study of the mechanism of action of any agent that causes disturbance in the regeneration of an amphibian limb can also provide clues to the manner in which that agent might be affecting the development of that structure and other organs/systems in human and other embryos.

Several substances which adversly affect development in mammalian embryos also produce similar effects in the regenerating amphibian limbs (Chang et al 1955; Deck and Shapiro 1963). Gebhart and Faber (1966) had conducted studies on axolotl to determine whether regenerating limb could be a suitable system for testing the teratogenicity of a number of drugs. Some had no effect and others retarded growth with or without causing malformations or defects in the regenerates. Interestingly, aminopterin, an analogue of folic acid caused polydactyly when given at cone-blastema stage but oligo- and syndactyly when given at paddle stage of regeneration. Simultaneous administration of folic acid and aminoprotein prevented the effects of the latter.

Amphibians are very useful animals for investigating the effects of any substance on development and also regeneration of limbs. In these animals hind limbs develop in the free swimming larval phase of life outside the body, and their morphogenesis and growth can be observed from the initial bud stage onward in living individuals. On young tadpoles the effect of the substance on both ontogenetic development and regeneration of limbs in the same individual can be studied and compared by keeping the rudiment of one limb intact and amputating through that of the contralateral side. Effects on tail regeneration can also be studied in the same individuals and compared with that on limbs.

Apart from exploring the possible teratogenic effects of vitamin A excess, an important objective of our studies was to investigate whether and how this chemical might influence the sequential processes and events involved in regeneration of tail and 
limbs and also certain special features of this phenomenon in the tadpoles of frogs and toads. Although regeneration of a structure essentially follows the steps of its initial development, there are also differences between the two. Whereas ontogenesis proceeds from undifferentiated embryonic cells, the cells for regeneration are derived from already differentiated tissues in the stump of the structure concerned. Emerging from the disintegrating tissues of the stump after amputation, these cells must go through a certain degree of dedifferentiation and proliferation before morphogenesis and redifferentiation of the removed part can begin. In the case of limb regeneration these early postamputation processes lead to the formation of a blastema consisting of a mass of apparently similar mesenchymal cells accumulated below an apical epidermal cap (AEC) formed over the wound surface. The missing part is then formed from this blastema. The process is somewhat different in the case of tail regeneration in the anuran tadpoles. Unlike the ammocoete larvae of lampreys (Niazi 1963) and urodeles (Holtzer 1959) tail regeneration in anuran tadpoles does not involve the formation of blastema. Instead, the cells emerging from the different stump tissues remain recognizable and each tissue of the regenerated portion is formed from cells directly derived from the corresponding tissue in the stump (Niazi 1965, 1966).

Amphibians are famous for their power of limb regeneration. However, while newts and salamanders (urodeles) retain this ability throughout life, in the frogs and toads (anurans) it is present only in the tadpoles in which it gradually declines proximodistally along the limb axis with age and completely disappears before metamorphosis. The reasons behind this loss are not fully understood; but it has been suggested that the loss may be due to some or all of several factors such as specialization of limb tissues with age, insufficient number of cells derived from stump tissues, their inadequate dedifferentiation and proliferation, lack of development of AEC, premature differentiation of fibrous tissue below the wound epithelium and/or rising level of thyroid hormone in the body with the approach of metamorphosis (Schmidt 1968).

I had been interested in these problems of regeneration in anuran amphibians since my own doctoral studies on tail regeneration in ammocoetes and frog larvae carried out under the inspiring guidance of Professor N J Berrill at McGill University in Canada. The frog and toad tadpoles provide the interesting opportunity of studying the post-amputation events in limbs that have good or reduced ability of regeneration and also in those limbs from which it has disappeared completely. It was considered that some of the known properties of vitamin A, such as stimulation of release of lysosomal enzymes, dissolution of bone and cartilage, promotion of cell proliferation and inhibition of thyroid development, might influence in some way the processes involved in regeneration. Therefore, the aim was to find how vitamin A excess would affect post-amputation processes and events that lead to good or hypomorphic regeneration of the removed part as well as those which result only in wound healing and no regeneration.

When we began the studies it was not one of the objectives to explore whether vitamin A excess can alter pattern formation in the regenerates developing from the blastema. At that time there was no basis even for such speculation. Much later, we learnt from a review article of Faber (1976) about the reported findings of de Both (1970) and Dinsmore (1974). These workers had observed some forearm and upper arm skeletal elements in the regenerates developed from wrist level blastemas grafted in groups or in combination with minced muscle in the eye orbit in axolotls. In their opinion, appearance of proximal elements in these regenerates in violation of the Rule 
of Distal Transformation of Blastema may have been due to increased amount of mesenchyme and more severe dedifferentiation. Supporting this 'mass effect' hypothesis, Faber (1976) had visualized the possibility of appearance even of shoulder girdle elements in regenerates developing from a distal level blastema if its mesenchymal mass could be sufficiently increased. Motivated by this we re-examined the bizarre results of one of our previous experiments. We discovered that in some cases vitamin A treatment had resulted in regenerates having an unexpectedly altered morphological pattern. In these cases complete limbs had regenerated from shank level blastemas. This finding provided an additional objective for our studies, viz., investigation of various aspects of pattern-altering effect of vitamin A on limb regeneration.

The initial studies made on tail regeneration showed that continuous treatment with vitamin A palmitate after tail amputation inhibited regeneration allowing some growth of only the fin which formed a peculiar pouch. The inhibitory effects were produced primarily during dedifferentiation of cells emerging from the stump tissues (Niazi and Saxena 1968, 1979). In this brief retrospect I present the results of some of our studies which provided important information on the effects of vitamin A on limb regeneration and development in frog and toad tadpoles.

\section{Materials and methods}

The general methodology followed was to immerse the tadpoles in aqueous suspensions of the required amounts of vitamin A palmitate (hereafter referred to as the retinoid), for various periods. The hind limbs of the treated and control tadpoles were amputated through thigh, shank or ankle in similar ways in each experiment and the morphological and histological effects on regeneration of amputated and development of unoperated hind limbs were studied. Controls were always reared in plain water. The highest concentration of the retinoid that the tadpoles of any age could tolerate with least mortality was $15 \mathrm{IU} / \mathrm{ml}$.

\section{Effects on limb regeneration}

The initial studies on the effects of hind limb regeneration were made on somewhat older tadpoles of the toad, Bufo andersonii, in collaboration with Saroj Saxena. In these tadpoles the regenerative power was nearly absent in the thigh but it was quite good in the shank segment. After amputation through mid-thigh or mid-shank of both legs in each case the tadpoles were kept in $151 \mathrm{U} / \mathrm{m} 1$ suspension continously for 15 days. Regeneration from thigh stumps failed in all control as well as treated tadpoles. It occurred in all cases from shank stumps; but in contrast to controls the regenerates of treated tadpoles were mere spikes or were severely oligodactylous and distorted in shape. Unfortunately, their skeletal structure was not examined by in toto staining or sectioning. Microscopic study of the operated limbs sectioned during the first week after amputation revealed that, as in controls, all the changes conducive to regeneration had occurred in the treated cases as well. They included the specific wound healing pattern, dedifferentiation and formation of good blastema at both thigh and shank levels. The blastemas contained many cells in mitosis. However, the subsequent processes of redifferentiation and morphogenesis were delayed at shank level and completely suppressed at thigh level (Saxena 1973; Saxena and Niazi 1977). 
The exciting initial discovery of the pattern altering effect of the retinoid on regenerating limbs came from the results of another experiment performed on a small number of young tadpoles of $B$. andersonii, in which the tiny hind limbs had been amputated through the shank region (Niazi and Saxena 1978). These tadpoles were placed in $15 \mathrm{IU} / \mathrm{ml}$ retinoid suspension after amputation but during the subsequent 4 weeks the retinoid was not replenished and only water was added every day to maintain the level of the rearing medium. The regenerates of the treated group were very different from those of controls. They were ill-developed, small and strangely abnormal. In 6 out of 14 cases multiple regenerates appeared to be growing from each stump. At first, these cases were interpreted as just some very bizarre examples of teratogenic effects of the retinoid (Saxena 1973). Later, after reading the review by Faber (1976), another look at the photographs of these regenerates produced the exciting realization that some of them, though retarded and abnormal, were in fact complete limbs consisting of all segments including thigh, shank and foot and not just the parts distal to the amputation level (figures 1,2). It appeared as if the retinoid had facilitated the acquisition of greater than usual developmental potency by the blastema enabling it to form a complete limb instead of only the foot.

Meanwhile, O P Jangir had joined me for his doctoral studies. Enthused by the above findings we decided to test the effects of the retinoid on development and regeneration of limbs by varying the time of start and duration of treatment. Young Bufo melanostictus tadpoles of stage 30/31 (Khan 1965), when the hind limbs are at spatula/food-paddle stage, were used in the experiments. One limb was amputated and the other kept intact in each tadpole. The blastema had been found to develop in 3 days. Therefore, following amputation through shank region, one group of tadpoles was
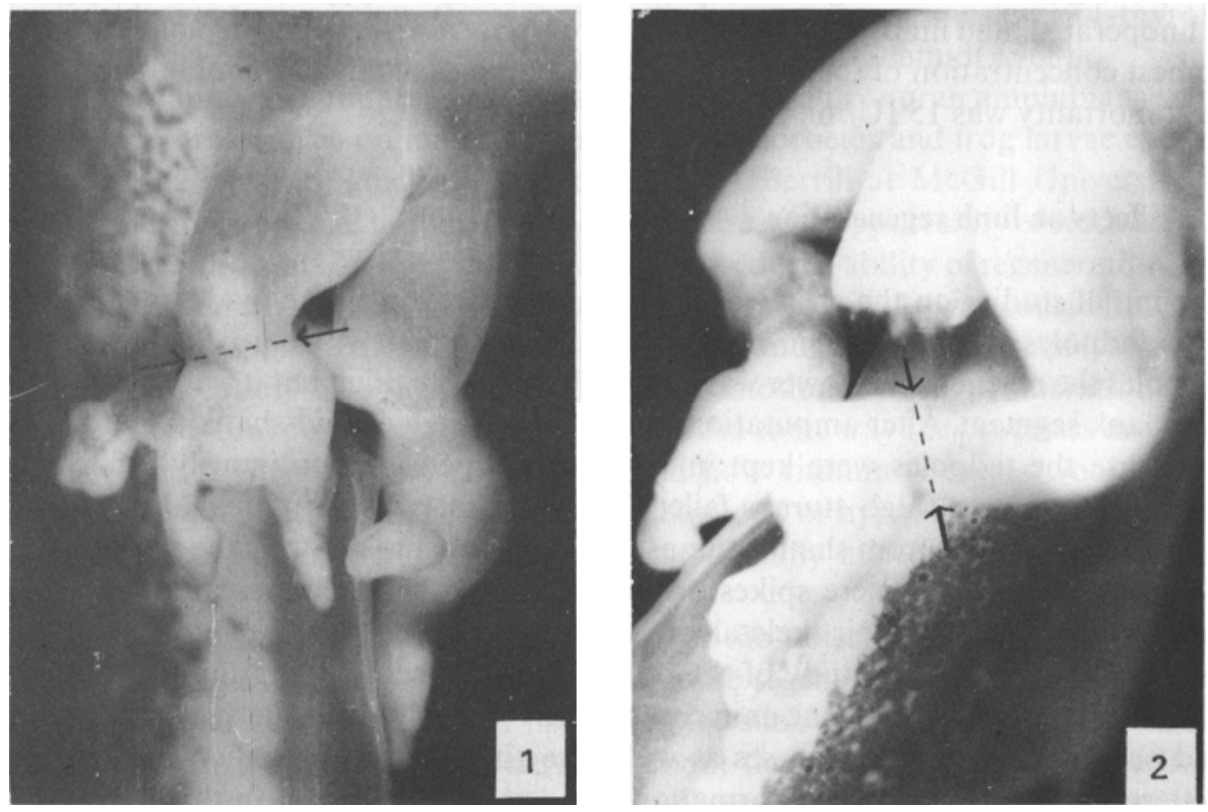

Figures 1 and 2. Abnormal limb regenerates of young B. andersonii tadpoles after shank level amputation (broken line). Note the limb in (2) has all limb segments, viz., thigh, shank and foot (from Niazi and Saxena 1978). 
placed in $15 \mathrm{IU} / \mathrm{ml}$ retinoid suspension immediately and the second group 3 days later continuously up to the end of the experiment. The third group was placed in the retinoid suspension only during the first 3 days post-amputation and thereafter reared in plain water.

The results (table 1), first reported by Jangir and Niazi (1977) showed that perfect regenerates had developed in the controls as usual (figure 3). Blastema formation had occurred in all the three groups of treated tadpoles. Whereas (i) continuous treatment for the entire period immediately and also from 3 days after amputation had completely inhibited further progress of regeneration in all so treated tadpoles (ii) good regenerates had developed in the cases treated only during the first 3 days when the blastema was forming. Two features of these regenerates were exciting: (i) All of them were complete limbs containing all the proximal parts including the girdle serially duplicated (figure 4). This phenomenon is now referred to as P-D duplication or proximilization. (ii) In 14 out of 42 cases 2 , and in one case 3 such complete limbs had regenerated from each stump. The twins were mirror images of each other (figures 5,6). The retinoid had altered the pattern of limb regenerates along P-D as well as A-P axes. Similar findings were later made in urodeles and frog tadpoles by several workers (Maden 1982, 1983; Thoms and Stocum 1984; Kim and Stocum 1986; Lheureux et al 1986; Ludolph et al 1990).

Table 1. Effect of treatment of stage $30 / 31$ B. melanostictus tadpoles with $15 \mathrm{IU} / \mathrm{ml}$ vitamin A palmitate for different periods on the development of foot in the unoperated and regeneration from the amputated contralateral limb on day 0 (after: Jangir and Niazi 1978).

\begin{tabular}{lcccccc}
\hline & $\begin{array}{c}\text { Days of post- } \\
\text { amputation } \\
\text { treatment }\end{array}$ & $\begin{array}{c}\text { Survivors } \\
\text { on day 15 }\end{array}$ & $\begin{array}{c}\text { Foot development } \\
\text { in intact limbs }\end{array}$ & $\begin{array}{c}\text { Regeneration from } \\
\text { amputated limbs }\end{array}$ \\
\hline 1 & $0-15$ & 64 & 0 & 64 & 0 & Inhibited \\
2 & $4-15$ & 35 & 35 & 0 & Normal & Inhibited \\
3 & $0-3$ & 42 & 0 & 42 & $42^{*}$ & 0 \\
4 (control) & Nil & 57 & 57 & 0 & 57 & 0 \\
\hline
\end{tabular}

*These were complete limbs. In 14 cases two and in one case three regenerates had developed per stump. Controls were reared in plain water throughout.

The results confirmed the earlier findings on $B$. andersonii tadpoles and clearly demonstrated that: (i) The retinoid treatment does not inhibit but actually promotes the process of blastema formation; (ii) if the treatment continues beyond blastema stage it inhibits its redifferentiation and morphogenesis; and (iii) although the blastema of treated cases appears similar to that of controls it is very different from the latter in respect of its morphogenetic potency which may be even equal to that of the original limb bud capable of forming a complete limb. The retinoid must be inducing such changes in the cells derived from stump tissues during their dedifferentiation and blastema formation (Jangir and Niazi 1978; Jangir 1979). This was confirmed by a later study made with Professor. D L Stocum and Dr M J Prescitelli on Pleurodeles and axolotl larvae using retinoic acid during my stay at the University of Illinois, UrbanaChampaign, USA during 1983-84 on an Indo-US Fellowship. RA produced proximalizing effects on regenerates when given up to late blastula stage but it became inhibitory when given with the beginning of redifferentiation (Niazi et al 1985). Also, 

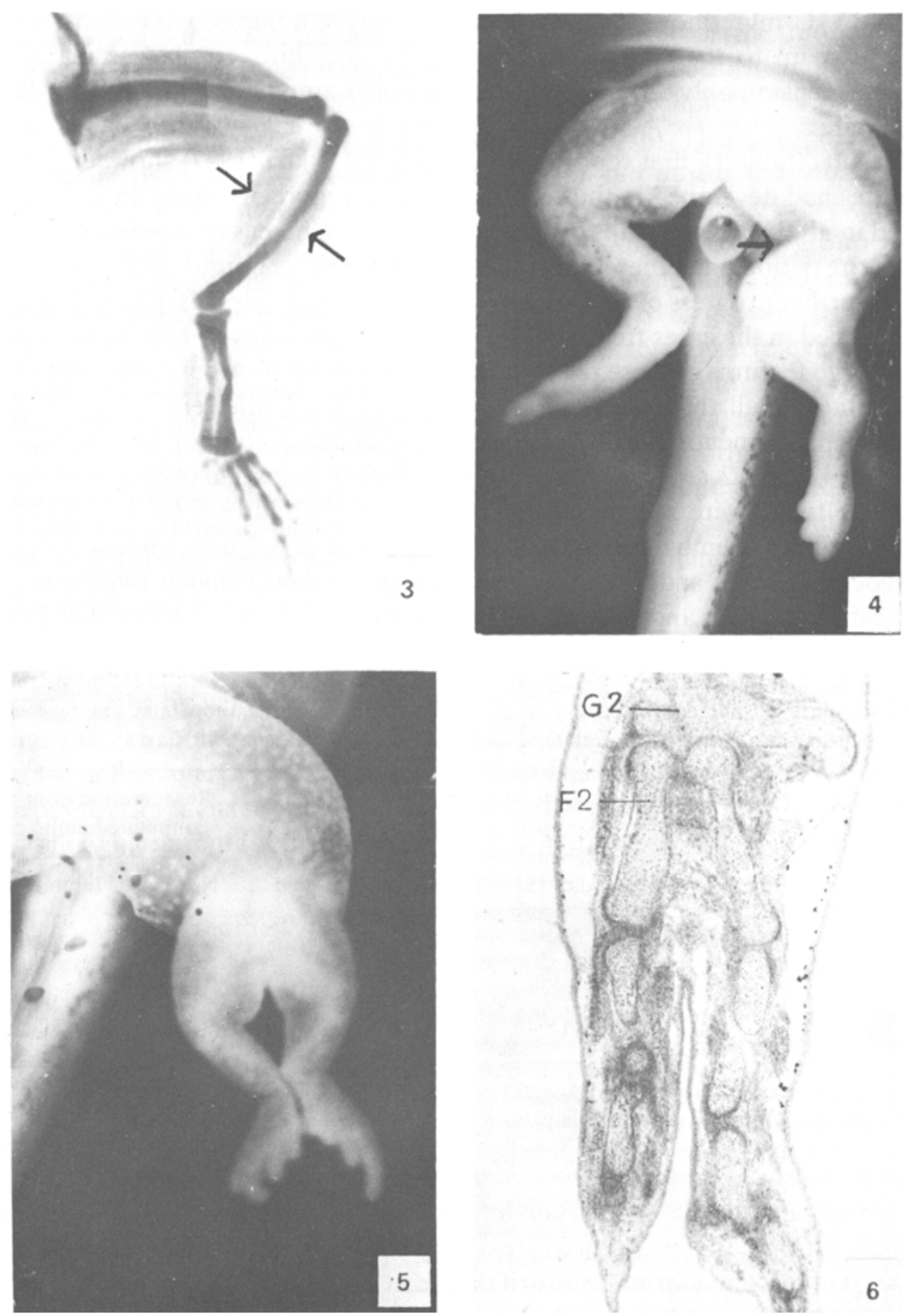

Figures 3-6. (3) Victoria blue stained normal limb regenerate of a control young B. melanostictus tadpole amputated (arrow) through shank region. (4 and 5) Proximalized single (4) and twin mirror imaged (5) regenerates of young B. melanostictus tadpoles treated with vitamin A for 3 days after amputation through shank region. Regenerates are complete limbs having thigh, shank and foot. Note the foot morphogenesis in the unoperated limb (4) was inhibited (arrow indicates level of amputation). (6) LS though another case of proximalized twin regenerates of vitamin A treated B. melanostictus tadpole after shank level amputation. Note duplicated femurs (F2) articulating with duplicated girdle (G2). 
the results of an experiment in which the tadpoles were treated for 2 days after the wound healing stage post-amputation have suggested that the pattern altering effect is induced during dedifferentiation of blastema cells (Niazi and Ratnasamy 1984).

The results of these experiments posed a number of questions which stimulated and oriented the subsequent investigations carried out in collaboration with O P Jangir and later with K K Sharma, Shaheen Alam and Charles Ratnasamy who joined me to do research for their doctoral degrees.

3.1 We asked whether the treated blastema has the autonomous self-organizing capacity to produce proximalized regenerates if grafted in an ectopic location

This was tested on young, stage 30/31 tadpoles of B. melanostictus first by O P Jangir and later by Shaheen Alam (Jangir 1979; Alam 1983; Niazi 1983). O P Jangir removed shank level blastemas of the tadpoles treated with $15 \mathrm{IU} / \mathrm{ml}$ retinoid for 3 days and auto-grafted them into the enucleated eye orbits of the same tadpoles. Following grafting the tadpoles were transferred to plain water. En the later experiments Shaheen Alam grafted the blastemas from treated and untreated tadpoles homoplastically into enucleaed eye orbits of treated and untreated host tadpoles. The treated blastemas grafted auto- or homo-plastically into the orbits of treated or untreated hosts differentiated into regenerates containing proximal in addition to distal limb structures. In many cases they were complete limbs even containing a girdle; and in some cases good mirror-imaged twins had developed from the same graft. The untreated blastemas even if grafted in the orbit of treated hosts formed only distal parts, usually the foot or only digits (figures 7-10).

3.2 Would the retinoid cause proximalization of regenerates after amputation through any P-D level of the limb? And is this effect related to the duration of treatment?

Answers to these queries were sought in a detailed study on young Rana breviceps tadpoles (Sharma 1982; Sharma and Niazi 1988). Different groups of tadpoles at stage VIII/IX (according to Taylor and Kollros 1946) were treated with $15 \mathrm{IU} / \mathrm{ml}$ retinoid for periods ranging from $1 \mathrm{~h}$ to $72 \mathrm{~h}$ following amputations through thigh, shank and ankle. Proximalizing effect of the retinoid was seen in all the regenerates from all 3 amputation levels. However, continuous immersion of operated tadpoles in the retinoid suspension for various periods actually produced 3 types of regenerates: (i) Normal (N-type) consisting of only distal parts like controls, (ii) Proximalized (P-type)--single or multiple regenerates per stump containing some or all parts of the stump serially duplicated in the regenerate(s) in addition to distal parts, and (iii) inhibited cases (PB-type) which persisted as blastemas without morphogenesis or histogenesis. The results are presented in table 2. Treatment for one hour produced only N-type regenerates in all cases but its increasing duration progressively reduced their number to zero and simultaneously caused the production of P-type and PB-type regenerates in different proportions at the 3 amputation levels varying according to length of treatment. Continuous $72 \mathrm{~h}$ exposure to the retinoid produced inhibiting effect on regeneration resulting in more than $2 / 3$ cases of PB-type at each amputation level. However, a restricted exposure of $12 \mathrm{~h} /$ day for 3 days induced P-type regeneration in $100 \%$ cases at thigh, shank as well as ankle levels. 

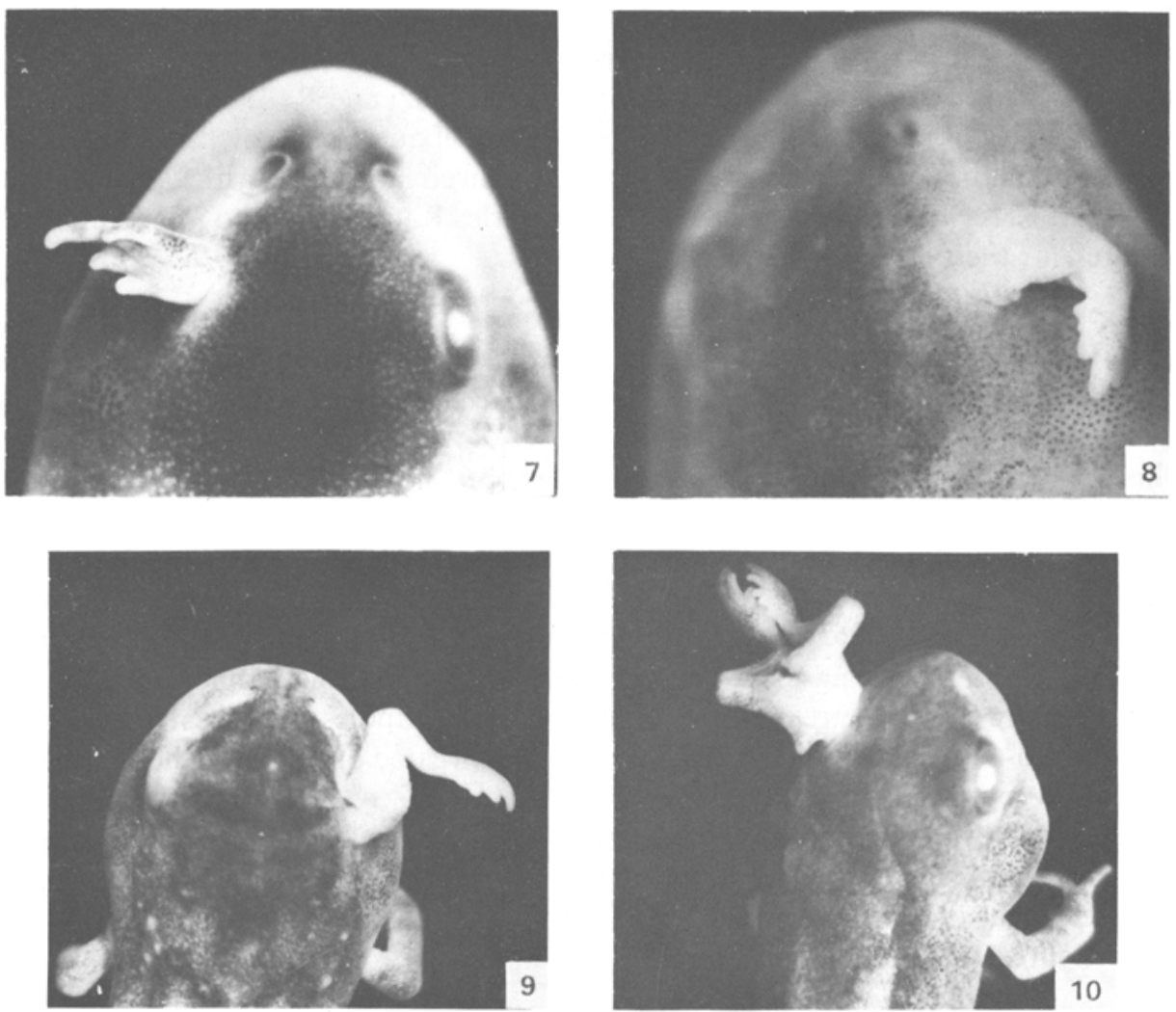

Figures 7-10. Regenerates formed by shank level blastemas of untreated and 3 days 15 $\mathrm{IU} / \mathrm{m} 1$ vitamin A treated donor tadpoles of $B$. melanostictus homoplastically grafted into enucleated eye orbits of previously treated or untreated host tadpoles. Note only distal part of foot was formed by untreated $(\mathbf{7})$ but complete single $(\mathbf{8 , 9}, \mathbf{9})$ and twin regenerates $(\mathbf{1 0})$ by treated blastemas. (7) Donor-untreated; host-untreated. (8) Donor-treated; host-untreated. (9, 10) Donors-treated; hosts untreated.

Proportions of the 3 types of regenerates obtained at the thigh, shank and ankle levels of amputation resulting from 6-72h continuous treatment did not show a P-D pattern conforming to the respective positions of these segments along the limb axis. Surprisingly, the shank level blastemas appeared to be the most sensitive to inhibiting as well as proximalizing influence of the retinoid. The inhibiting effect expressed in the frequency of PB-type was found to be the dominant feature in the shank-level amputees given a shorter $(48 \mathrm{~h})$ treatment than in thigh and ankle level amputees, in which this occurred after a longer $(72 \mathrm{~h})$ exposure to the retinoid. Whereas $6 \mathrm{~h}$ treatment induced P-type regenerates in a number of shank and thigh level amputees - twice as many at the former $(20 \%)$ as at the latter $(10 \%)$ level, the first few such cases $(3 \%)$ appeared at ankle level only with $24 \mathrm{~h}$ treatment. The highest frequency of P-type regenerates at shank level was observed in the tadpoles treated for $24 \mathrm{~h}$, but at thigh and ankle levels it occurred after $48 \mathrm{~h}$ treatment (see table 2 ). The results indicated that the sensitivity of the blastemas from the 3 P-D limb segments was shank $>$ thigh $>$ ankle. 
Table 2. Proportions of different regenerate types in young $R$. breviceps tadpoles treated with $15 \mathrm{IU} / \mathrm{ml}$ vitamin A palmitate for different periods after amputation through thigh shank and ankle (after Sharma 1982; Sharma and Niazi 1988).

\begin{tabular}{|c|c|c|c|c|c|c|c|}
\hline \multirow[b]{2}{*}{$\begin{array}{l}\text { Amputation } \\
\text { level }\end{array}$} & \multirow[b]{2}{*}{$\begin{array}{l}\text { Regenerate } \\
\text { type }\end{array}$} & \multicolumn{6}{|c|}{$\begin{array}{c}\text { Regenerate types obtained after various periods of } \\
\text { treatment }(\%)\end{array}$} \\
\hline & & $6 \mathrm{~h}$ & $12 \mathrm{~h}$ & $24 \mathrm{~h}$ & $48 \mathrm{~h}$ & $72 \mathrm{~h}$ & $\begin{array}{l}12 \mathrm{~h} / \text { day } \\
\text { for } 3 \text { days }\end{array}$ \\
\hline \multirow[t]{3}{*}{ Mid-thigh } & P-type & 10 & 23 & 53 & 77 & 31 & 100 \\
\hline & N-type & 85 & 64 & 32 & 7 & 0 & 0 \\
\hline & PB-type & 5 & 13 & 15 & 16 & 69 & 0 \\
\hline \multirow[t]{3}{*}{ Mid-shank } & P-type & 20 & 56 & 95 & 40 & 27 & 100 \\
\hline & N-type & 80 & 44 & 5 & 0 & 0 & 0 \\
\hline & PB-type & 0 & 0 & 0 & 60 & 73 & 0 \\
\hline \multirow[t]{3}{*}{ Mid-ankle } & P-type & 0 & 0 & 3 & 73 & 32 & 100 \\
\hline & N-type & 100 & 100 & 97 & 2 & 0 & 0 \\
\hline & PB-type & 0 & 0 & 0 & 25 & 68 & 0 \\
\hline
\end{tabular}

P, Proximalized; N, normal, like controls; PB, inhibited blastemas.

Controls similarly operated, reared in plain water throughout, produced only N-type regenerates.

Similar results were obtained by Alam (1983) in experiments on young B. melanostictus tadpoles of stage 30/31 (equivalent to stage VIII/IX of Taylor and Kollros 1946). She found that in these young Bufo tadpoles too shank level blastemas were the most and ankle level blastemas the least sensitive to proximalizing action of the retinoid on regeneration. However, comparison between the results on B. melanostictus with those on Rana breviceps, described above, showed that the tadpoles of the two species of equivalent developmental stages differ in their susceptibility to identical treatment with the retinoid: whereas 3 days exposure to $15 \mathrm{IU} / \mathrm{ml}$ retinoid was quite inhibitory for Rana, causing PB-type results in more than $2 / 3$ cases at each amputation level, in the Bufo tadpoles the same treatment induced good P-type regenerates in the highest number of cases at each level [thigh (90\%), shank (95\%) and ankle (56\%)], and the inhibitory effect became dominant only later after 4 days treatment (Niazi et al 1989).

\subsection{Are the retinoid effects related to its concentration?}

This was investigated on stage $30 / 31$ tadpoles of $B$. melanostictus by treating them with 5, 10 and $15 \mathrm{IU} / \mathrm{ml}$ retinoid for 1-4 days after amputation through shank (Alam 1983). Concentrations of 5 and $10 \mathrm{IU} / \mathrm{ml}$ caused similar effects as $15 \mathrm{IU} / \mathrm{ml}$ but with relatively longer treatment. Four days treatment with these lower concentrations resulted in a good number of N-type and P-type regenerates whereas the same length of exposure to $15 \mathrm{IU} / \mathrm{ml}$ was extremely inhibitory resulting in $85 \%$ cases of PB-type (table 3 ).

3.4 Can the retinoid induce regeneration in limbs which do not have this power? Can it improve regenerative ability in tadpole limbs in which it is declining?

In the recently metamorphosed froglets of Rana cyanophlyctis and $R$. breviceps external application of highly concentrated retinoid on the wrist stumps for a few days 
Table 3. Various regenerate types obtained in $B$. melanostictus tadpoles treated with different concentrations of vitamin A palmitate for 1 to 4 days after amputation through mid-shank (after Alam 1983).

\begin{tabular}{|c|c|c|c|c|c|}
\hline \multirow[b]{2}{*}{ Type } & \multirow{2}{*}{$\begin{array}{c}\text { Dose } \\
(\mathrm{IU} / \mathrm{ml})\end{array}$} & \multicolumn{4}{|c|}{ Regenerate types (\%) } \\
\hline & & day & 2 days & 3 days & 4 days \\
\hline \multirow[t]{3}{*}{ P-type } & 5 & 16 & 32 & 41 & 54 \\
\hline & 10 & 19 & 38 & 56 & 69 \\
\hline & 15 & 50 & 80 & 95 & 15 \\
\hline \multirow[t]{3}{*}{ N-type } & 5 & 84 & 68 & 59 & 41 \\
\hline & 10 & 81 & 56 & 31 & 12 \\
\hline & 15 & 50 & 0 & 0 & 0 \\
\hline \multirow[t]{3}{*}{ PB-type } & 5 & 0 & 0 & 0 & 5 \\
\hline & 10 & 0 & 6 & 13 & 19 \\
\hline & 15 & 0 & 20 & 5 & 85 \\
\hline
\end{tabular}

P, Proximalized; N, normal; PB, inhibited blastemas.

Controls similarly operated and reared in plain water produced only

N-type regenerates.

post-amputation could induce small but definitive regenerative growth (Niazi et al 1979; Sharma and Niazi 1979).

Retinoid treatment of stage XIII/XIV $R$. breviceps tadpoles was able to induce the development of imperfectly formed but P-type regenerates in a few cases after amputation through thigh which otherwise had already lost the power to regenerate almost completely (Sharma 1982; Sharma and Niazi 1988).

A detailed study was conducted on B. melanostictus tadpoles of stages 30/31, 34, 36 and 38 (Khan 1965) to see the effects of retinoid after amputation through thigh, shank and ankle (Alam 1983; Alam and Niazi 1989). The capacity to regenerate is high throughout the length of the hind limb at stage 30/31 but declines proximo-distally as the tadpoles grow, and it is completely absent at stage 38 (Alam and Niazi 1980). After amputations the tadpoles were immersed in $15 \mathrm{IU} / \mathrm{ml}$ for 3 days and transferred to plain water thereafter. The controls were operated similarly and reared in plain water throughout. The results obtained in stages 34 and 36 are presented in table 4 and some representative regenerates are shown in figures 11-15. They provided the following information:

(i) In each limb segment the normal pattern of decline of regenerative capacity is manifested in the increasing oligodactyly of the regenerates and decreasing percentage of amputees regenerating at all.

(ii) Proximalizing effect of the retinoid on regeneration appeared to be correlated with the presence and degree of the natural ability to regenerate at any limb level. The percentage of P-type regenerates was reduced as the ability to regenerate declined and no such regenerate developed from any amputated level in the tadpoles of stages 36 and 38. Concomitantly, the percentage of N-type regenerates increased.

(iii) The retinoid also exercises an improving influence on the regenerative ability. This was expressed in larger number of amputees regenerating and higher percentage of perfect pentadactylus cases among the N-type regenerates in the treated tadpoles 
Table 4. Regenerate types obtained in B. melanostictus tadpoles of stages 34 and 36 treated with $15 \mathrm{IU} / \mathrm{m} 1$ vitamin A palmitate for 3 days after amputation through thigh, shank and ankle (after Alam 1983; Alam and Niazi 1989).

\begin{tabular}{|c|c|c|c|c|c|c|c|}
\hline \multirow[b]{2}{*}{ Stage } & \multirow{2}{*}{$\begin{array}{l}\text { Amputation } \\
\text { level }\end{array}$} & \multirow[b]{2}{*}{ Group } & \multirow{2}{*}{$\begin{array}{l}\text { Limbs } \\
\text { regenerating } \\
(\%)\end{array}$} & \multicolumn{3}{|c|}{$\begin{array}{l}\text { Regenerate type in } \\
\text { treated tadpoles } \\
(\%)\end{array}$} & \multirow{2}{*}{$\begin{array}{l}\text { Pentadactylous } \\
\text { cases among } \\
\text { control and } \\
\text { N-type treated } \\
\text { regenerates } \\
(\%)\end{array}$} \\
\hline & & & & $\mathrm{P}$ & $\mathrm{N}$ & PB & \\
\hline \multirow[t]{6}{*}{34} & \multirow[t]{2}{*}{ Thigh } & Control & 100 & - & - & - & 40 \\
\hline & & Treated & 100 & 16 & 36 & 48 & 67 \\
\hline & \multirow[t]{2}{*}{ Shank } & Control & 100 & - & - & - & 47 \\
\hline & & Treated & 100 & 60 & 12 & 28 & 100 \\
\hline & \multirow[t]{2}{*}{ Ankle } & Control & 100 & - & - & - & 67 \\
\hline & & Treated & 100 & 76 & 8 & 24 & 100 \\
\hline \multirow[t]{6}{*}{36} & \multirow[t]{2}{*}{ Thigh } & Control & 43 & - & - & - & 0 \\
\hline & & Treated & 52 & 0 & 53 & 47 & 14 \\
\hline & \multirow[t]{2}{*}{ Shank } & Control & 67 & - & - & - & 30 \\
\hline & & Treated & 72 & 0 & 100 & 0 & 50 \\
\hline & \multirow[t]{2}{*}{ Ankle } & Control & 73 & - & - & - & 27 \\
\hline & & Treated & 85 & 0 & 100 & 0 & 59 \\
\hline
\end{tabular}

P, Proximalized; N, normal; PB, inhibited blastemas.

Controls similarly operated and reared in plain water.

of stages 34 and 36 as compared to corresponding controls. The proximalized regenerates are most usually well-formed and pentadactylous.

(iv) When the regenerative ability was completely absent the retinoid could still induce some regeneration in a few or more cases at all 3 amputation levels at least in the form of blastema-like out-growths or small spikes in the tadpoles of stage 38 .

3.5 Does the retinoid cause its proximalizing effect when administered only after amputation or would treatment only prior to amputation produce a similar effect?

In one study on B. melanostictus tadpoles of stages $30 / 31$ and 34 and were treated with $15 \mathrm{IU} / \mathrm{ml}$ retinoid for 3 days only prior to amputation through shank. This produced P-type regenerates in $76 \%$ cases in the tadpoles of stage $30 / 31$ and in $53 \%$ cases in those of stage 34. This also indicated that the retinoid action is exercised through some systemic route and direct action on stump tissues exposed by amputation is not essential (Alam 1983; Niazi and Alam 1984).

3.6 Does the effect of retinoid persist for any length of time after cessation of treatment?

The answer to this question was obtained by a series of experiments (Jangir 1979; Alam 1983; Niazi et al 1989). After amputation through shank the young stage 30/31 B. melanostictus tadpoles were placed in $15 \mathrm{IU} / \mathrm{ml}$ retinoid for 3 days and thereafter transferred to plain water. A second amputation was then performed through shank 

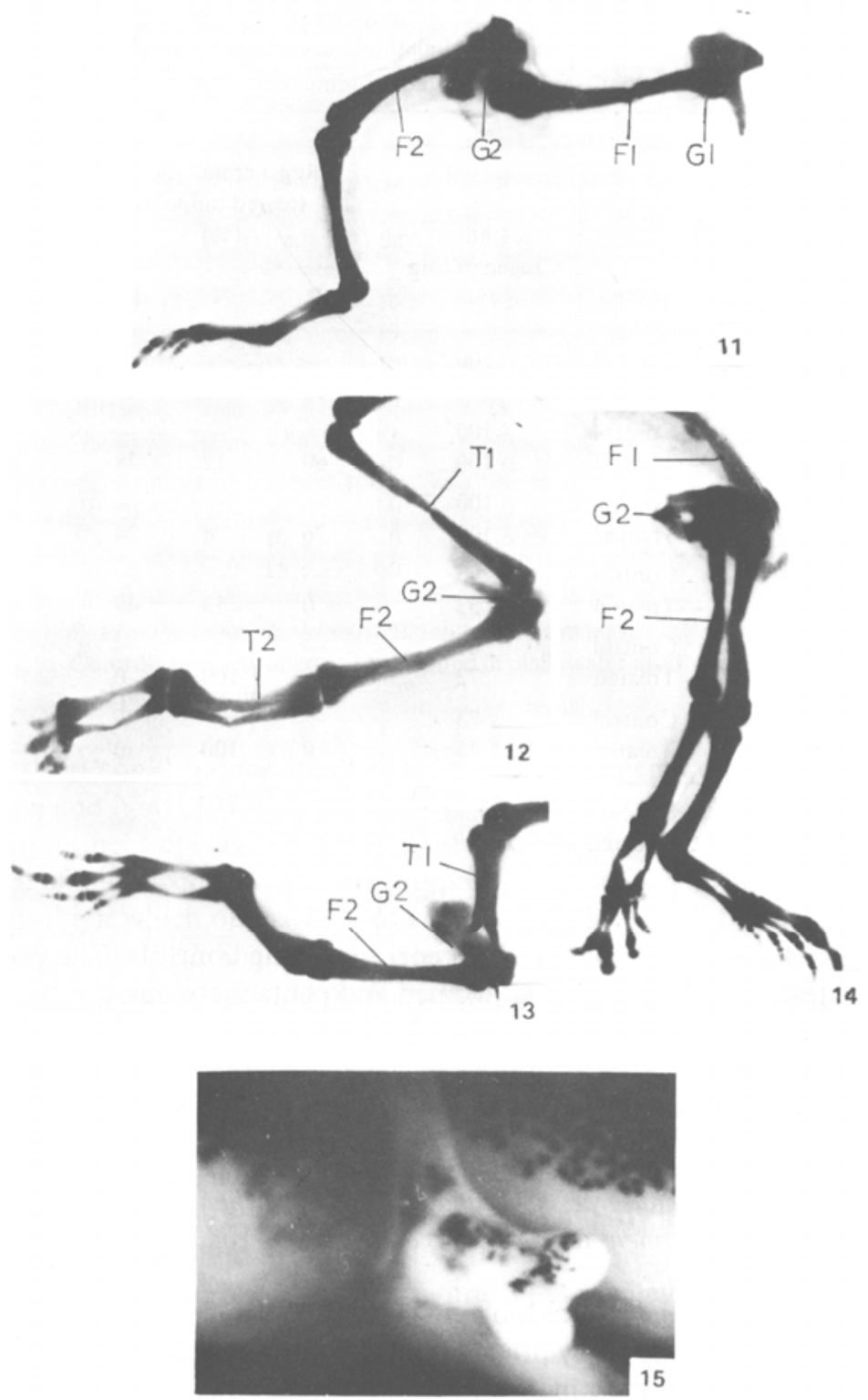

Figures 11-15. (11-14) Victoria blue stained preparations of skeletons of complete hind limb regenerates of $B$. melanosticto tadpoles. Limb was amputated below the knee at stage 30/31 (11), through ankle at stage 34 (12) and through shank at stage 30/31 (13). The twins (14) regenerated after amputation through thigh at stage 30/31. The tadpoles were treated with $1511.1 / \mathrm{m} 1$ vitamin A palmitate for 3 days post-amputation. F1, original and F2, duplicated femurs; 01, original and G2, duplicated girdle; T1, original and T2, duplicated tibio-fibula. (15) A case of undifferentiated 15 days old twin blastemas formed on the amputated thigh stump of a B. melanostictus tadpole treated with $15 \mathrm{IU} / \mathrm{ml}$ vitamin A for 3 days. 
again (a little behind the proximal boundary of the regenerating part). The second amputation was made in different groups at various intervals-immediately (day 0) and $1,3,5,9$ and 13 days after the cessation of treatment. Control groups were similarly operated.

The results (table 5) showed that the influence of the retinoid persisted, but in a declining manner up to 13 days. This was reflected in the production of P-type, N-typeand PB-type cases in varying proportions after the second amputation. With increasing age the regenerative ability of the tadpoles progressively declined. In the 9-day group just about $21 \%$ of the controls regenerated; but regeneration of P-type, N-type or at least PB-type occurred in $100 \%$ cases in all treated tadpoles reamputated on any of the 0-13 days after cessation of treatment. However, the frequency of good P-type regenerates declined progressively with increasing delay in the second amputation indicating persistent but gradually decreasing retinoid influence. During the same period the frequency of N-type regenerates among the reamputated cases increased up to 5 days after cessation of treatment before decreasing.

In another experiment young Bufo tadpoles were treated with $15 \mathrm{IU} / \mathrm{ml}$ retinoid for 3 days following amputation through ankle and thereafter transferred to plain water. The operated limbs were immediatly reamputated but this time some through ankle and others through the more proximal segments, shank or thigh. Controls were operated similarly. P-type regenerates developed from all 3 levels of second amputation but in decreasing numbers as the level of amputation became more proximal (ankle $=62 \%$, shank $=40 \%$ and thigh $=15 \%$ ), and simultaneously the incidence of $\mathrm{N}$-type and PB-type regenerates increased as the level of second amputatin became more proximal. This indicates not only the persistence of retinoid influence but also that it affects the tissues immediately in the vicinity of the wound as well as tissues of the

Table 5. Regeneration in the hind limbs following amputation through shank in stage $30 / 31$ B. melanostictus tadpoles transferred to water after 3 days treatment with $15 \mathrm{IU} / \mathrm{ml}$ vitamin A palmitate and reamputation through shank on days $0-13$ at various intervals after cessation of treatment (compiled from Alam 1983; Niazi et al 1989).

\begin{tabular}{llcccc}
\hline \multirow{2}{*}{$\begin{array}{l}\text { Day of } \\
\text { reamputation }\end{array}$} & Group & $\begin{array}{c}\text { Reamputated } \\
\text { regenerating } \\
\text { limbs (\%) }\end{array}$ & \multicolumn{2}{c}{ Regenerate types of treated tadpoles (\%) } \\
\cline { 5 - 6 } & Control & 100 & - & - & - \\
\hline 0 & Treated & 100 & 75 & 14 & 11 \\
1 & Control & 100 & - & - & - \\
& Treated & 100 & 64 & 25 & 11 \\
3 & Control & 94 & - & - & - \\
& Treated & 100 & 50 & 38 & 12 \\
5 & Control & 52 & - & - & - \\
& Treated & 100 & 28 & 44 & 28 \\
9 & Control & 21 & - & - & - \\
& Treated & 100 & 8 & 23 & 69 \\
13 & Control & 0 & - & - & - \\
& Treated & 100 & - & - & 100 \\
\hline
\end{tabular}

P, Proximalized; N, normal, PB, inhibited blastemas.

Controls similarly operated and reared in plain water. 
entire residual limb; and this effect is expressed phenotypically in the P-type regenerates when the limb is amputated through any segment, inducing commencement of regeneration at that level.

\section{Effects on limb development}

Very useful and interesting information was obtained on the effects of excess retinoid on the normally developing limbs of tadpoles. Its retarding effect on growth of limbs and thyroid glands was observed in an early study (Niazi and Saxena 1972). However, very intriguing results were obtained in the experiments on young B. melanostictus tadpoles beginning at spatula/paddle stage of hind limbs in which one leg was amputated and the other was kept intact (Jangir and Niazi 1978). In this study the tadpoles were treated with retinoid at and for different periods after amputation (table 1). Continuous immersion for the entire experimental period inhibited regeneration from the amputated limb and also morphogenesis of the foot but did not affect further development of the proximal segments of the intact limb. While the treatment given for only the initial 3 days also inhibited foot morphogenesis in the intact limb, it promoted regeneration of complete limbs from the amputated limb (figures 4, 17, 18, 20, 21). Finally, while treatment beginning 3 days after the start of experiment prevented regeneration, it had no effect on further development of the foot of the intact limb. Defective development of the foot in the unoperated legs and also digits of the hands was observed in all subsequent experiments on tadpoles of spatula/paddle stage of development in which only one hind limb was amputated and not more than 3 days treatment was given immediately thereafter.

Jangir (1978) had noted that at spatula/paddle stage the toe rudiments were not yet visible and internally, the chondrogenic condensation was just beginning in the foot region. Exposure to the retinoid at this stage inhibited further development of the foot; but tissues of the proximal segments which were at a higher stage of differentiation at that time were not affected. By the time the treatment started 3 days later the foot morphogenesis had also advanced and so its further development was not affected in this case.

The above results indicated that the cells of any prospective limb region are susceptible to the inhibitory influence of retinoid only at some specific stage of differentiation. It led us to investigate whether a one day treatment with the retinoid $(15 \mathrm{IU} / \mathrm{ml})$ beginning at very early stages of limb development would produce cases in which the foot may have developed normally but one or the other proximal segment was affected. As expected, we did obtain cases (unpublished) in which ankle + foot were normal but shank or thigh was absent or very short-defects similar to those caused by thalidomide in humans. Figure 19 shows one such case in which the shank is missing in the malformed hindlimbs and hands are also defective.

The results indicate that the mesodermal cells of the entire limb bud from its base to apex are not sensitive to the inhibitory influence of retinoid at the same time. It seems that this sensitivity arises in the presumptive cells of the various regions of the developing limb sequentially and proximodistally, and lasts for a short time disappearing similarly before overt histogenesis begins in each region. A brief exposure to a suitable dose of the retinoid at an early stage might produce only a defective thigh with the shank and foot remaining unaffected. By a somewhat later stage when the cells of the next prospective segment, viz., shank, have acquired this sensitivity those of the thigh 

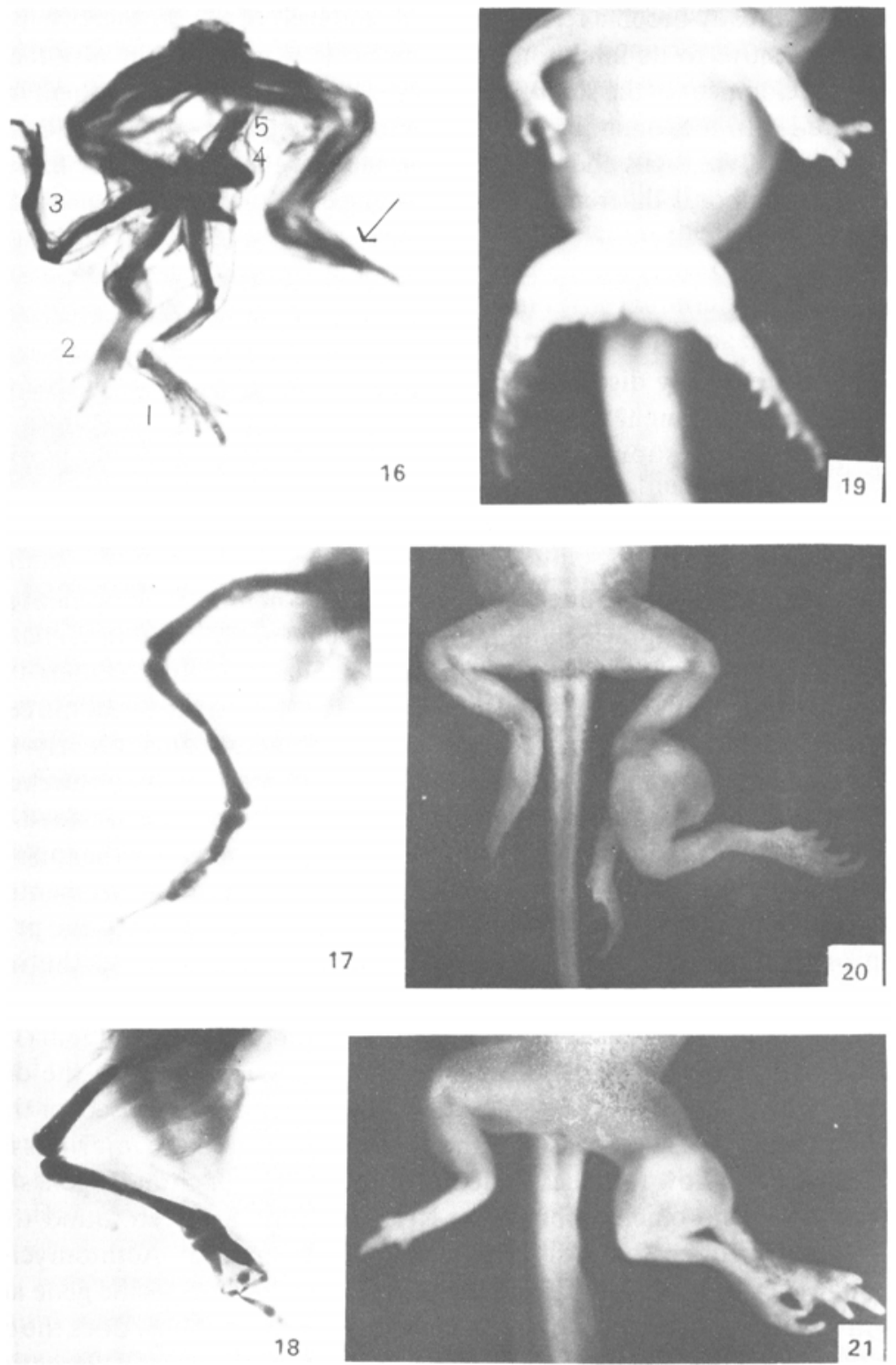

Figures 16- 21. (16) Victoria blue stained skeleton of a bizarre case of multiple regenerates of a $B$. melanostictus tadpole amputated through shank after 3 days treatment with $15 \mathrm{IU} / \mathrm{ml}$ vitamin A. Note inhibited foot in the unoperated limb (arrow). Five limbs had regenerated from the operated limb, three of which $(1,2,3)$ were well developed. $(\mathbf{1 7}, \mathbf{1 8})$ Note defective foot in B. melanostictus tadpoles treated with $15 \mathrm{IU} / \mathrm{ml}$ vi tamin A palmitatc for 2 days (17) and on the 2 nd and 3rd days (18) after spatula/paddle stage of hind limb development. (19) A case of $R$. breviceps tadpole treated with $15 \mathrm{IU} / \mathrm{ml}$ vitamin A palmitate for one day at an early hind limb bud stage. Note ankle + foot is well formed, shank is missing and thigh is very short. Hand digits show syndactyly. (20, 21) Two cases of twin regenerates of stage 34 B. melanostictus tadpoles treated with $15 \mathrm{IU} / \mathrm{ml}$ vitamin A palmitate for 3 days after amputation through ankle (20) and shank (21). Note perfect feet of regenerates but inhibited foot development of unoperated right limbs. 
region may have already become referactory to it, and cells of the prospective foot region may still be insensitive to its inhibiting influence. This would explain why the retinoid inhibited the development of the shank level but did not affect the foot or thigh in the case shown in figure 19. In the forelimbs of this case the same treatment caused defect in the most distal structure, viz. digits and had no effect on either the upper arm or forearm. This must be due to temporal difference between the speeds of development of fore- and hindlimb buds.

\section{Discussion}

It is appropriate to briefly discuss some of the interesting and unexpected effects of retinoid on limb development and regeneration observed during the studies reviewed and to indicate some questions arising from them which call for further work.

\subsection{Sensitivity to teratogenic influence of retinoid}

Vitamin A excess is found to produce teratogenic effects on limb development as well as regeneration in anuran tadpoles. Similar effects have been observed in Xenopus laevis tadpoles and the larvae of Ambystoma mexicanum (Scadding and Maden 1986). We observed that on the regenerating limbs this effect is exerted on the blastema cells at the onset of redifferentiation; and in the developing limb bud during early stages of differentiation. The entire limb bud mesoderm from base to apex, however, is not sensitive to the injurious influence of retinoid at the same time. Instead, like the direction of the progress of determination and differentiation along the limb bud this sensitivity arises in the presumptive cells of the various limb regions/segments sequentially and proximodistally; and it disappears too in the same way with the progress of differentiation. The origin as well as disappearance of sensitivity to the inhibiting influence of retinoids are thus the outcome of a certain degree of differentiation of tissues in each case in every region of the developing limb. Kistler and Galli (1979) had observed that the sensitivity of cartilaginous humeri of rat fetuses to the degrading effect of retinoic acid (RA) decreased with age. The problems are to discover the nature of changes that make cells first sensitive and then insensitive to the injurious influence of retinoid excess; and how its effect is mediated. Inhibition of chondrogenesis in limb mesenchyme of rat and chick embryos by RA in culture has been found to involve DNA-, RNA- and protien synthesis which can be prevented by Actinomycin D and cyclohexamide (Lewis et al 1978; Gallandre and Kistler 1980). Specific gene activity is obviously involved in the inhibiting action of retinoid. Why and how does the excessive retinoid induce such specific gene activity only at a certain stage of differentiation?

Teratogenesis by retinoid excess has been studied for long in mammals. Our studies on Bufo and Rana and of others on Xenopus and axolotl suggest that the normally developing and regenerating hind limbs of amphibians can be very suitable models for investigations to understand the mechanism of teratogenic action of retinoids.

\subsection{Increase in morphogenetic capacity of regeneration blastema}

Retinoid treatment not extending beyond the blastema stage not only produced opposite effects on the development of intact and regeneration of amputated limbs in the same individual tadpoles, but also clearly demonstrated that the Rule of Distal 
Transformation of Blastema is not irrevocable. This rule can be experimentally subverted to such an extent that the blastema becomes equivalent to the original limb bud capable of forming a complete limb in situ as well as when grafted ectopically. Post-amputation processes observed in the treated and untreated regenerating limbs leading to formation of blastema in each case are basically similar. Although the blastema cells of both untreated and treated cases look alike they are radically different from each other in their morphogenetic capacity. Whereas the blastema of the former can form only distal structures, that of the latter can form some or all proximal parts as well. This poses the very obvious questions: What is the material (structural/biochemical/molecular) basis of this difference between the two blastemas? And how does the retinoid cause this difference?

The apparent difference in the post-amputation events noticed in the treated as compared to untreated cases were more severe disintegration of stump tissues, seemingly greater density of cells in the blastema and delay in the onset of redifferentiation. Also, increased and prolonged mitotic activity was noted in the blastema of treated cases (Alam 1983; Sharma et al 1990-91). Similar observation was reported by Koussoulakos (1989) in the salamander Triturus alpestris. Are increased and prolonged mitotic activity and delayed redifferentiation involved in any way in the enhancement of morphogenetic potency of the retinoid treated blastemas? Et may be recalled that transdetermination of Drosophila imaginal disc cells also involves many mitotic cycles.

Originally, we had expressed the opinion that retinoid treatment increases the potency of the blastema by causing more intense dedifferentiation of its cells and reactivating all the limb-forming genes (Niazi and Saxena 1978; Jangir and Niazi 1977, 1978; Jangir 1979). Encreased acid phosphatase activity in the treated blastemas of frog tadpoles was noted by Sharma (1982). Such activity is correlated with the process of dedifferentiation in regenerating limbs (Schmidt 1968). Later authors have also expressed similar views (Maden 1982; Kim and Stocum 1986). Dedifferentiation of cells, a prerequisite for regeneration, involves biosynthetic changes in the cells expressed in the production of new RNAs and protiens. These changes must be directed and controlled by certain genes reactivated under the influence of amputational injury and subsequent events. Normally perhaps just those genes are reactivated which direct the formation of only the missing part distal to the amputational level. However, depending upon its intensity, retinoid treatment probably reactivates the full complement of limb-forming genes in the blastema cells. The question is: what may be the restricting factor(s) which determine just how much developmental capacity is reawakened in the blastema cells to enable formation of only distal structures?

It is now well known that RA affects gene activity and is involved in pattern formation and regulation. A proximodistal gradient of endogenous RA has been observed in the developing as well as regenerating axolotl limbs. Is endogenous RA essential for limb regeneration in amphibians? Ef so, does the quantitative level of endogenous RA existing in the cells at any amputation level of the limb determine the limit of gene reactivation, set the proximal boundary of the regenerate and thus permit the formation of parts only distal to that level? Ef it be so, perhaps the amount of RA in cells/tissues at any level of amputation might be the molecular basis of the Rule of Distal Trnasformation of Blastema. Administration of additional exogenous retinoid might raise the quantitative level of RA in the cells/tissues sufficiently throughout the limb. This would create material conditions coducive to reactivation of more or all limb-forming genes in the dedifferentiating cells originating at any amputation level 
and form a blastema with morphogenetic potency enhanced to an unusual extent. Comparative studies on these lines in anuran and urodele amphibians may also provide an insight into the possible reasons behind the loss of limb regeneration capacity in the anuran tadpoles before metamorphosis and its absence in adults.

\subsection{Retinoid treated blastema-a self-organizing independent entity}

It was noted that very often the P-D and A-P axes of the proximalized regenerates were not aligned with those of the stump. It appeared as though the treated blastema was haphazardly grafted on the distal end of the stump and grew in the direction of its own choice. The regeneration of the P-type regenerates often commenced from a level somewhat proximal to the cut end of the stump. Occasionally this was seen in very bizarre cases of numerous regenerates developing from the same stump in all sorts of directions (figure 16). This suggests that the polarities of the treated regenerates may not be determined by those of the stump, and that the treated blastema is a completely self-organizing structure totally independent of any influence of the stump.

\subsection{Variations in regenerative response to retinoid treatment}

In addition to P-type regenerates, N- and PB-type were also produced in the tadpoles of identical ages amputated through the same limb segment and given exactly the same treatment. Since proximalizing effect is proportional to retinoid concentration and duration of treatment, atleast some specific amount reaching the blastema cells must be necessary to affect the relevant genes to cause any degree of change in the regenerate pattern. Lesser amounts taken up by cells may have little or no effect resulting in the $\mathrm{N}$-type regenerates. Too much intake may damage the cellular machinery at the transcriptional, translational or post-translational levels resulting in the absence of redifferentiation in the blastema which may persist as such (PB-type) or its cells may become necrotic. Vasan (1981) had found that treatment with vitamin A acetate in culture irreversibly altered the chick embryo sternal chondrocytes to prechondrogenic mesenchymal morphology and proteoglycans synthetic activity. Ealier, Lewis et al (1978) had also observed failure of chondrogenic differentiation of limb bud mesenchyme pretreated with vitamin A. En both these cases it is probable that the concentration of vitamin A may have been too high. Ide (1988) has observed differentiation of cartilaginous nodules in chick limb bud mesenchyme cultured with low amount of RA.

Occurance of one or the other of the 3 types of regenerates may be attributed to differential intake or assimilation of the retinoid by different individuals of the same tadpole population. However, this alone cannot be a satisfactory explanation in view of the finding that (i) the proportions of $\mathrm{P}, \mathrm{N}$ and $\mathrm{PB}$-type results varied according to the limb segment through which amputation was made even in tadpoles of the same stage given identical treatment; and (ii) in older tadpoles their respective frequencies appeared to be correlated with the extent of natural ability to regenerate in any limb segment. It may be recalled that among the blastemas formed from cells derived from stump tissues after amputation through thigh, shank and ankle in treated tadpoles the shank level blastemas were found to be the most sensitive to proximalizing, and later, to inhibiting influence of the retinoid. In axolotls too the blastema cells derived from tissues of zeugopodial segment of fore as well as hind limbs were found to be most 
sensitive to proximalizing action of retinoid as compared to those derived from stylopodial and autopodial tissues (Maden 1982; Kim and Stocum 1986). At this stage of our knowledge it is not possible to say what may be the basis of observed differences in the variety of morphogenetic effects produced at different amputation levels in tadpoles of the same stage by identical retinoid treatment. Maybe they are related to some unknown differences in the nature of cells and tissues of various limb segments from which blastema cells are derived in the tadpoles of any stage of development.

\subsection{Multiple regenerates from the same stump}

Another interesting feature was the development of multiple regenerates from the same stump in many treated cases but never in the controls. Such regenerates were always of P-type and often they were complete limbs. Multiple regenerates per stump have also been found to occur in retinoid treated young larvae of Rana temporaria and Xenopus among anurans (Maden 1983; Scadding and Maden 1986) and Pleurodeles and axolotl among urodeles (Lheureux et al 1986; Kim and Stocum 1986). The factors responsible for this phenomenon must be operative during blastema formation. In fact, we have seen more than one blastemas per stump in some cases as early as 2-3 days after limb amputation. If the post-blastemic development was inhibited these remained as undifferentiated blastemas (figure 5) with sparse or necrotic cells. Twin mirror image limbs can be made to develop from one limb bud by dividing the apical ectodermal ridge (AER) by a mechanical barrier, and similarly an accessory regenerate can be obtained from the same stump by transplanting an additional apical epidermal cap (AEP) on the blastema (Thornton 1968) without retinoid or any other kind of treatment. Therefore, while specific gene activity must also be involved in this phenomenon, a possible mechanical disturbance in the pattern of wound healing after amputation in the treated cases may also be an important factor. The retinoids cause more than usual destruction and regression of stump tissues. This might affect the migration of epidermal cells on the amputation surface and formation of the AEP. One or more epidermal tongues may penetrate deep into the regressing tissues of the wounded stump resulting in the formation of multiple AEPs adjacent to but separated from each other by such persistent tongue (s). Dedifferentiating cells emerging from stump tissues may then accumulate beneath each such cap and form multiple blastemas on the same stump, each of which may then form a regenerate. Such disturbance in wound healing pattern would be expected more often in cases where amputation surface is relatively large, tissues ar more sensitive to the local destructive action of the retinoid and the treatment is more intense. This agrees well with what has been actually observed. Frequency of multiple regenerates arising from the same stump was high at shank and thigh levels (larger wound surface), and much less or rare at ankle level (smaller wound surface); and more such cases occurred after treatment with higher retinoid concentration and/or for longer time.

\subsection{Improvement and revival of regenerative ability}

Retinoid treatment improved regenerative ability in the limbs in which it was low and could revive it to some extent in advanced tadpoles. Improvement was manifested in greater numbers regenerating, as well as more N-type regenerates of the treated groups 
possessing better formed feet than the corresponding controls (Sharma et al 1985; Alam and Niazi 1989; see table 4). This improvement may have been due to more severe disintegration of stump tissues releasing greater number of cells, more intense dedifferentiation, increased and prolonged mitotic activity and delayed redifferentiation in the relatively better formed blastema. Moreover, a short 3-day exposure of tadpoles to 15 $\mathrm{IU} / \mathrm{m} 1$ retinoid was found to retard the growth of thyroid glands and delay metamorphosis (Alam 1983; Sharma and Niazi 1983; Gupta 1991). The consequent hypothyroid condition in the tadpoles may have facilitated the formation of an adequate blastema, and delayed redifferentiation providing sufficient time for proper morphogenesis of the regenerates.

\subsection{Persistence of retinoid influence}

Persistence of the influence of retinoid was reflected in the development of proximalized regenerates when limbs of pretreated tadpoles were amputated or reamputated up to some days after cessation of treatment. These results indicated that the retinoid treatment affects the tissues of the entire limb and not just those in the immediate vicinity of amputation level. We have suggested earlier (Niazi et al 1989) that treatment with additional exogenous retinoid may perhaps induce some profound but temporary and reversible change(s) of quantitative/qualitative nature in the cell surface, cytoplasm or nuclear chromatin which destroy or modify the supposed positional values in the cells of tissues of the entire limb. These changes may then be the basis for manifestation of the characteristic retinoid effects on limb regeneration when it is initiated by amputation through any level in the pretreated tadpoles up to a certain time after cessation of treatment. Johnson and Scadding (1992) have also found effectiveness of proximalizing effect of retinoid on limb regeneration in axolotls up to 1-2 weeks after cessation of treatment. They have attributed this to the high residual levels of retinoid in the body during this period. However, they have also suggested that the retinoid may have caused temporary modification of the positional values in the plasma membrane of cells of limb tissues via its effect on the genome which, under the influence of residual retinoid, may have led to the development of proximalized regenerates in pretreated axolotls. Further investigations are required to find whether this type of regeneration is due to persisting residual retinoid and/or any alteration(s) already produced in the pretreated limb tissues. Studies are needed to find what kind of changes, if any, are produced by retinoid treatment in the cells and tissues of unamputated limbs or the residual parts of amputated regenerating limbs.

Retinol palmitate (RP) was used in our experiments on Bufo tadpoles and also by Johnson and Scadding (1992) on axolotls. RP is stored in the liver and can persist in the circulating blood and tissues for a good length of time. E may suggest that for such studies a one time injection of retinoic acid (RA) may be more useful since RA is not stored and is metabolized rapidly and removed from the body (see Niazi et al 1985).

I may conclude with the opinion that it was a very significant finding that in a developing system the effect on morphogenesis which the retinoid excess can produce on dedifferentiating cells can be fundamentally opposite to the effect it produces on cells that are in the early stages of differentiation. The retinoid exerted inhibitory influence on the cells of limb bud at an early stage of differentiation during ontogenesis, and also on blastema cells at the onset of redifferentiation during regeneration- causing teratogenic effects in both cases. On the contrary, suitable retinoid treatment not extending beyond blastema formation not only promoted regeneration, but, most remarkably, altered the pattern of limb 
regeneration. The pattern altering effect of the retinoid was expressed in the development of serially duplicated some or all proximal parts of the residual limb stump of the regenerates in addition to the removed distal part irrespective of the amputation level. There is strong evidence that the pattern altering effect of the retinoid is produced in the dedifferentiating cells as they emerge from stump tissue to form the blastema, and is mediated via its influence on some specific pattern forming genes. Since the processes of limb development in tetrapods and amphibian limb regeneration are similar, the mechanism involved in pattern generation in these appendages may also be identical. In view of this the discovery of the ability of retinoids to alter pattern predictably along specific axes in regenerating limbs was of tremendous significance. It made available to developmental biologists for the first time a reliable group of chemical probes in the retinoids, and in amphibian limb regeneration a suitable system for investigations of the molecular mechanisms responsible for the genesis of pattern. Dedifferentiation is a prerequisite for regeneration in all animals which have this ability and, therefore, perhaps other regenerating systems can also be employed for such investigations.

\section{Acknowledgements}

The studies were supported by research grants from the University Grants Commission and the Council of Scientific and Industrial Research, New Delhi to the author and Research Fellowships to O P Jangir, K K Sharma, Shaheen Alam and Charles Ratnasamy. I must also acknowledge the assistance of my wife, Dr Sultana Niazi and children in preparation of the manuscript.

\section{References}

Alam S 1983 Studies on the morphogenetic influence of treatment of tadpoles of the anuran Bufo melanostictus Schneider with vitamin A palmitate on limb regeneration, $\mathrm{Ph} \mathrm{D}$ thesis, University of Rajasthan, Jaipur

Alam S and Niazi I A 1980 The pattern of decline and loss of the capacity for hind limb regeneration in the tadpoles of Bufo melanostictus Schneider; Rajasthan Univ. Stud. Zool. 2 105-113

Alam S and Niazi I A 1989 The various effects of retinol palmitate on hind limb regeneration in Bufo melanostictus tadpoles of different developmental stages, in Proceedings of Seventh All India Symposium of Development Biologists (eds) R P Maleyvar and S C God (Kurukshetra: Indian Society of Developmental Biologists) pp 123-132

Brockes J P 1989 Retinoids, homeobox genes and limb morphogenesis; Neuron 2 1285-1294

Chang C Y, Witschi E and Ponseti I V 1955 Teratogenic effects of Lathyrus odoralus seeds on development and regeneration of vertebrate limbs; Proc. Soc. Exp. Biol. Med. 90 45-50

Cohlan S Q 1953 Excessive intake of vitamin A as a cause of congenital anomalies in the rat; Science 117 535-536

de Both N J 1970 The developmental potencies of the regeneration blastema of the axolotl; Roux's Arch. 164 $242-276$

Deck J D and Shapiro S L 1963 Interference with newt limb regeneration by an inhibitor of histamine formation; Anat. Rec. 145307

Drill V A 1943 Interrelationships between thyroid function and vitamin metabolism; Physiol. Rev. 23 355-379

Dinsmore C E 1974 Morphogenetic interactions between minced limb muscle and transplanted blastemas in the axolotl; J. Exp. Zool. 187 223-232

Eichele G 1993 Retinoids in embryonic development; Ann. N.Y. Acad. Sci. 678 22-36

Faber J 1976 Positional information in the amphibian limb; Acta Biotheor. 25 44-65

Fell H B and Rinaldini L M 1965 The effects of vitamin A and C on cells and tissues in culture; in Cells and tissues in cultures, methods, biology and physiology (ed.) E N Will mer (New York: Academic Press) vol 1, pp 659-699 
Gallandre F and Kistler A 1980 Inhibition and reversion of chondrogenesis by retinoic acid in rat limb bud cell cultures; Roux's Arch. Dev. Biol. 189 25-33

Gebhardt D O E and Faber J 1966 The influence of aminoprotein on limb regeneration in Ambystoma mexicanum; J. Embryol. Exp. Morphol. 16 143-158

Giroud A and Martinet M 1960 Teratogenic action of hypervitaminosis A in the mouse as a function of the embryonic stage; C. R. Soc. Biol. Paris 154 1353-1355

Gupta P 1991 Effects of vitamin A on the thyroid glands of anuran larvae, $\mathrm{PhD}$ thesis, University of Rajasthan, Jaipur

Holtzer H 1959 The development of mesodermal axial structures in regeneration and embryogenesis, in Regeneration in vertebrates (ed.) C S Thornton (Chicago: University of Chicago Press) pp 15-33

Ide H 1988 Retinoic acid promotes cell proliferation and cartilage nodule formation in the cultured chick embryo limb buds; in Regeneration and development (eds) S Inoui, T Shirai, M W Egar, S Aiyama, J Geraudie, T Nobunaga and N L Sato (Maebashi: Okada Printing and Publishing Co.) pp 521-529

Jangir O P 1979 Experimental studies on the ontogenesis of limbs in the anuran Bufo melanostictus (Schneider), $\mathrm{PhD}$ thesis, University of Rajasthan, Jaipur

Jangir O P and Niazi I A 1977 Increase in developmental potencies of blastemas of regenerating limbs in toad tadpoles exposed to vitamin A excess; 2nd All India Symposium on Developmental Biology, University of Poona, Pune, Nov. 1977 (Abstract no. 20)

Jangir O P and Niazi I A 1978 Stage dependent effects of vitamin A excess on limbs during ontogenesis and regeneration in tadpoles of the toad, Bufo melanostictus Schneider; Indian J. Exp. Biol. 16 438-445

Johnson K J and Scadding R S 1992 The duration of the effectiveness of vitamin A at causing proximo-distal duplication in regenerating limbs of the axolotl, Ambystoma mexicanum, in relation to whole body retinoid levels; J. Exp. Zool. 264 189-195

Kalter H C and Warkany J 1959 Experimental production of congenital malformations in mammals by metabolic procedures; Physiol. Rev. 39 69-115

Khan M S 1965 A normal table of Bufo melanostictus Schneider; Biologica 11 1-39

Kim W S and Stocum D L 1986 Effects of retinoids on regenerating limbs: comparison of retinoic acid and arotinoid at different amputation levels; Roux's Arch. Den. Biol. 195 455-463

Kistler A and Galli B 1979 Retinoic acid induced proteoglycan release and cartilage resorption in rat bone cultures are age dependent and inhibited by EDTA; Roux's Arch. Den. Biol. 187 59-71

Koussoulakos S 1989 Survey of research work on the regeneration of Triturus alpestris forelimbs treated with vitamin A palmitate; in Recent trends in regeneratton research (eds) V Kiortsis, S Koussoulakos and H Wallace (New York: Plenum Press) NATO-ASI Series, Series A: Life Sciences 172 355-370

Lewis C A, Pratt R M, Pennypacker J P and Hassell J R 1978 Inhibition of limb chondrogenesis in vitro by vitamin A: alteration in cell surface characteristics; Dev. Biol. 64 31-47

Lheureux E, Thorns S D and Cary F 1986 The effects of two retinoids in Pleurodeles waltz and Trturns vulgaris; J. Embryl. Exp. Morphol. 92 165-182

Ludolph D C, Cameron I A and Stocum D L 1990 The effect of retinoic acid on positional memory in the dorso-ventral axis of regenerating axolotl limbs; Dev. Biol. 140 41-52

Maden M 1982 Vitamin A and pattern formation in the regenerating limb; Nature (London) 295 672-675

Maden M 1983 The effects of vitamin A on limb regeneration in Rana temporaria; Dev. Biol. 98 409-416

Maden M 1989 Commentary on retinoids in regeneration, in Recent trends in regeneration research (eds) V Kiortsis, S Koussoulakos and H Wallace; NATO-ASI series, Series A: Life Sciences 172 371-373

Maden M 1993 The homeotic transformation of tails into limbs in Rana temporaria by retinoids; Dev. Biol, 159 379-391

Marin-Padilla M 1966 Mesodermal alterations induced by hypervitaminosis A; J. Embryol. Exp. Morphol. 15 261-264

McCarrison R 1923 Pathogenesis of deficiency diseases: No. XI-Observations on fatexcess in relation to iodine requirements to the thyroid glands; Indian J. Med. Res. 11 1-51

Mohanty-Hejmadi P, Dutta S K and Mahapatra P 1992 Limbs generated at the site of tail amputation in marbled balloon frog after vitamin A treatment; Nature (London) 355 352-353

Niazi I A 1963 The histology of tail regeneration in the ammocoetes; Can. J. Zool. 41 125-126

Niazi I A 1965 Muscle regeneration in frog tadpoles; Zool. Anz. 174 328-337

Niazi I A 1966 Role of notochord in regeneration of the tail in frog tadpoles; Acta Anat. 64 341-350

Niazi I A 1983 Regeneration studies in India, in Developmental biology - an Afro-Asian perspective (eds) S C Goel and R Bellairs: (Poona: Indian Society of Developmental Biologists) pp 161-176 
Niazi I A and Alam S 1984 Regeneration of whole limbs from shank stumps in toad tadpoles treated with vitamin A; Roux's Arch. Dev. Biol. 193 111-116

Niazi I A, Jangir 0 P, Alam S, Sharma K K and Ratnasamy C 1989 Vitamin A effect on limb regeneration: Studies on the tadpoles of anuran amphibians; in Recent trends in regeneration research (eds) V Kiortsis, S Koussoulakos and H Wallace (New York: Plenum Press); NATO-A SI series, Series A: Life Sciences 172 $355-370$

Niazi I A, Jangir 0 P and Sharma K K 1979 Forelimb regeneration at wrist level in the adults of skipper frog, Rana cyanophlyctis Schneider and its improvement by vitamin A treatment; Indian J. Exp. Biol. 17 435-437

Niazi I A, Pescitelli M J and Stocum D L 1985 Stage dependent effects of retinoic acid on regenerating urodele limbs; Roux's Arch. Biol. 194 355-363

Niazi I A and Ratnasamy C 1984 Regeneration of whole limbs in toad tadpoles treated with retinol palmitate after the wound healing stage; J. Exp. Zool. 230 501-505

Niazi I A and Saxena S 1968 Inhibitory and modifying influence of excess of vitamin A on tail regeneration in Bufo tadpoles; Experientia 24 852-853

Niazi I A and Saxena S 1972 The influence of excess vitamin A on the growth of frog tadpoles with particular reference to thyroid glands; Rev. Can. Biol. 31 89-96

Niazi I A and Saxena S 1978 Abnormal hind limb regeneration in tadpoles of the toad, Bufo anderosonii exposed to vitamin A excess; Folia Biol. (Krakow) 26 3-8

Niazi I A and Saxena S 1979 Relationship between inhibiting influence of vitamin A and developmental stage of regenerating tail in tadpoles (Bufo andersonii); Indian J. Exp. Biol. 17 866-868

Rose S M 1962 Tissue-arch control of regeneration in the amphibian limb; in Regeneration (ed.) D Rudwick (New York: Ronald Press) pp 153-176

Saxena S 1973 Studies on the influence of vitamin A on development, growth and regeneration in anura (Bufo andersonii Boulanger and Rana cyanophlyctis Schneider), $\mathrm{PhD}$ thesis, University of Rajasthan, Jaipur

Saxena S and Niazi I A 1977 Effect of vitamin A excess on hind limb regeneration in the tadpoles of the toad, Bufo andersonii Boulanger; Indian J. Exp. Biol. 15 435-439

Scadding S R and Maden M 1986 Comparison of the effect of vitamin A on limb development and regeneration in Xenopus laevis tadpoles; J. Embryol. Exp. Morphol. 91 35-53

Scadding S R and Maden M 1994 Retinoic acid gradients during limb regeneration; Dev. Biol. 162 608- 617.

Schmidt A J 1968 Cellular biology of vertebrate regeneration and repair (Chicago: University of Chicago Press)

Sharma K K 1982 Investigations on limb regeneration in tadpoles and froglets of the anuran Rana breviceps Schneider, treated with vitamin A or electrically stimulated, $\mathrm{Ph} \mathrm{D}$ thesis, University of Rajasthan, Jaipur

Sharma K K, Gaur M and Niazi I A 1990-91 Studies on the effect of vitamin A on mitotic activity of blastema cells during hind limb regeneration of Bufo melanostictus tadpoles; J. Zool. Soc. India 42-43 91-98

Sharma K K and Niazi I A 1979 Regeneration induced in the forelimbs by treatment with vitamin A in the froglets of Rana breviceps; Experientia 35 1571-1572

Sharma K K and Niazi I A 1983 Effect of vitamin A on metamorphosis in tadpoles of Rana breviceps; Natl. Acad. Sci. Lett. 6 397-399

Sharma K K and Niazi I A 1988 Variety of regenerative responses of different proximo-distal segments of young and advanced Rana breviceps tadpoles treated with vitamin A after amputation; in Control of cell proliferation and differentiation during regeneration (ed.) H J Anton (Basel: Kargen) Monogr. Dev Biol. 21 124-137

Sharma K K, Niazi I A and Sharma Y 1985 Improvement in morphology of hind limb regenerates of Rana breviceps tadpoles treated with vitamin A palmitate after amputation; in Recent advances in developmental biology of animals (eds) S C Goel and C B L Srivastava (Pune: Indian Society of Developmental biologists) pp 175-177

Tabin C J 1991 Retinoids, homeoboxes and growth factors: toward molecular models for limb development; Cell 66 199-217

Takekoshi S 1964 The mechanism of vitamin A induced teratogenesis; J. Embryol. Exp. Morphol. 12 263-271

Taylor S C and Kollros J J 1946 Stages in the normal development of Rana pipiens larvae; Anat. Rec. 94 7-23

Thoms S D and Stocum D L 1984 Retinoic acid induced pattern duplication in regenerating urodele limbs; Dev. Biol. 103 319-328

Thornton C S 1968 Amphibian limb regeneration; in Advances in morphogenesis (eds) M Abercombie and J Brachet (London: Academic Press) vol. 7, pp 205-219

Tickle C 1992 A tool for transgenesis; Nature (London) 358 188-189

Vasan N S 1981 Proteoglycan synthesis by sternal chondrocytes perturbed with vitamin A; J. Embryol. Exp. Morphol. 63 181-191 


\section{Further Related Reading, published previously in the Int. J. Dev. Biol.}

CYP26 function is required for the tissue-specific modulation of retinoic acid signaling during amphioxus development João E. Carvalho, François Lahaye, Jenifer C. Croce and Michael Schubert

Int. J. Dev. Biol. (2017) 61: 733-747

Synergistic action in P19 pluripotential cells of retinoic acid and Wnt3a on Cdx1 enhancer elements

Stephen J. Gaunt and Yu-Lee Paul

Int. J. Dev. Biol. (2014) 58: 307-314

Induction of intermediate mesoderm by retinoic acid receptor signaling from differentiating mouse embryonic stem cells Shiho Oeda, Yohei Hayashi, Techuan Chan, Minoru Takasato, Yuko Aihara,Koji Okabayashi, Kiyoshi Ohnuma and Makoto Asashima Int. J. Dev. Biol. (2013) 57: 383-389

Retinoic acid stability in stem cell cultures

Kyle A. Sharow, Boris Temkin and Mary Ann Asson-Batres

Int. J. Dev. Biol. (2012) 56: 273-278

Retinoid signalling is required for information transfer from mesoderm to neuroectoderm during gastrulation Ferran Lloret-Vilaspasa, Hans J. Jansen, Koen de Roos, Rosh A.S. Chandraratna, Maija H. Zile, Claudio D. Stern and Antony J. Durston Int. J. Dev. Biol. (2010) 54: 599-608

The expression of Stra6 and Rdh10 in the avian embryo and their contribution to the generation of retinoid signatures

Susan Reijntjes, Maija H. Zile and Malcolm Maden

Int. J. Dev. Biol. (2010) 54: 1267-1275

Morphogenetic action of retinoids and estrogens

$B$ van der Burg, E Sonneveld, J G Lemmen and P T van der Saag

Int. J. Dev. Biol. (1999) 43: 735-743

The use of a retinoid receptor antagonist in a new model to study vitamin A-dependent developmental events

D M Kochhar, H Jiang, J D Penner, A T Johnson and R A Chandraratna

Int. J. Dev. Biol. (1998) 42: 601-608

Treatment of axolotls with retinoids for limb regeneration studies

S R Scadding

Int. J. Dev. Biol. (1996) 40: 909-910
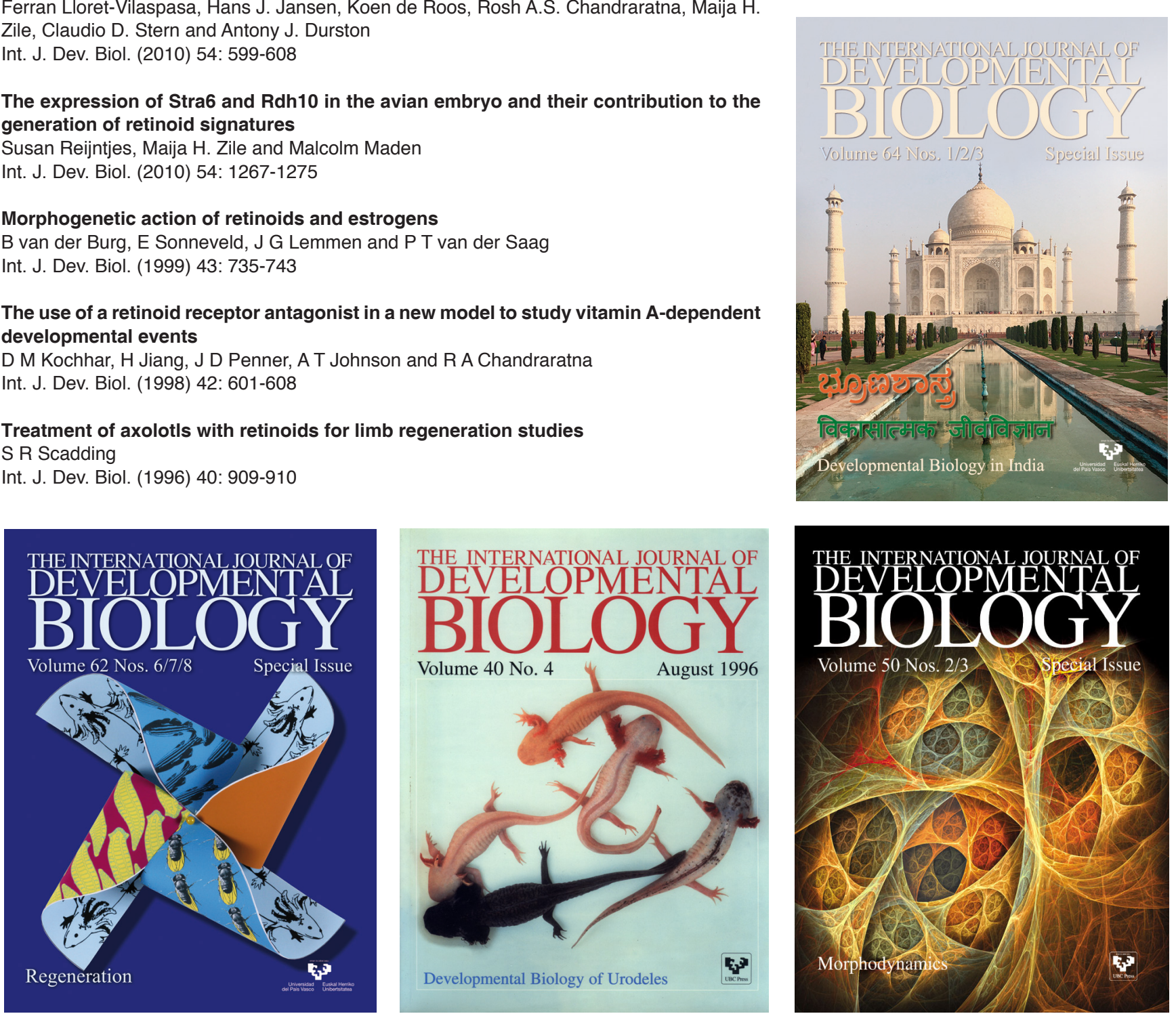